\title{
ICT and Gender: Parental Mediation Strategies
}

\author{
Eduarda Ferreira \\ Interdisciplinary Centre of Social Sciences (CICS.NOVA), \\ Faculty of Social Sciences and Humanities (FCSH/NOVA) \\ Lisbon, Portugal \\ e.ferreira@fcsh.unl.pt
}

\author{
Cristina Ponte \\ Interdisciplinary Centre of Social Sciences (CICS.NOVA), \\ Faculty of Social Sciences and Humanities (FCSH/NOVA) \\ Lisbon, Portugal \\ cristina.ponte@fcsh.unl.pt
}

\author{
Teresa Sofia Castro \\ Interdisciplinary Centre of Social Sciences (CICS.NOVA), Faculty of Social Sciences and Humanities (FCSH/NOVA) \\ Lisbon, Portugal \\ teresa.sofia.castro@gmail.com
}

\begin{abstract}
Information and communication technologies (ICT) continues to be a highly gendered area of life in all socioeconomic and educational backgrounds, and a source of significant social inequality in enduring ways. Parental mediation strategies can regulate the benefits and risks of the ICT for children, and have a significant and lifelong impact on children's self-confidence and positive attitudes toward digital technologies. This paper aims to explore how does gender, of both parents and children, affects parent mediation strategies of children's media use, adopting a critical discourse perspective in which gender differences in ICT use are understood as a result of gendertechnology and power-knowledge relations. We present a gender perspective on the results of the research 'Growing Up with Screens', conducted in Portugal which aims to explore the mediation practices of parents including the first generation of digital native parents with children aged 3 to 8 years old.
\end{abstract}

Keywords - Gender; ICT; stereotypes; parental mediation

\section{INTRODUCTION}

Information and communication technologies (ICT) are pervasive in every contexts and spaces and have revolutionized virtually every aspect of our life and work. To participate fully in the economic, social and cultural life people need the competences to navigate through a complex digital landscape. Nonetheless, ICT continues to be a highly gendered area of life in all socio-economic and educational backgrounds, and a source of significant social inequality in enduring ways. Nowadays, there are still differences between girls and boys in what concerns self-reported digital competences and experience with computers, even in countries where there is gender and socio-economic equality in access to school. These differences do not reflect material constraints, but rather students' interests and families' and educators' notions about what is suitable for them [1].

Parents are especially valued for their role in regulating the benefits and risks of the ICT for children, primarily within regulatory approaches that promote empowerment and selfregulation [2][3]. Parent mediation strategies of children's media use have a significant and lifelong impact on children's self-confidence and positive attitudes toward digital technologies.

The research 'Growing Up with Screens', conducted in Portugal and funded by ERC, aims to explore the mediation practices of parents including the first generation of digital native parents with children aged 3 to 8 years old. This paper reports on gender perspective on the results of the research 'Growing Up with Screens' focusing on how gender makes a difference on parental mediation of children's media use.

This paper aims to explore how does gender, of both parents and children, affects parent mediation strategies of children's media use. Our analysis adopts a critical discourse perspective in which gender differences in ICT use are understood as a result of gender-technology and powerknowledge relations. Gender and technology are both performative and mutually constitutive; i.e. gender is constitutive of what is recognized as technology, determining which skills are categorized as technological or not. The coproduction of gender and technology refers to the dialectical shaping of gender and technology, neither gender nor technology is taken to be pre-existing, nor is the relationship between them immutable [4]. This concept makes it possible to avoid the analytical pitfalls of essentializing either gender or technology [5][6].

The paper starts by reflecting on gender, digital practices and parental mediation. The report 'Growing Up with Screens' [7] is analysed using a gender sensitive perspective, aiming to disclose technologies as social constructions and the complexity of gender-technology relations. The paper goes on presenting the qualitative part of 'Growing Up With Screens' focusing on gender aspects of parental mediation. The conclusions reflect on the importance of gender stereotypes and parental mediation to promote gender in/equality in ICT access and use.

\section{GENDER, DIGITAL PRACTICES AND PARENTAL MEDIATION}

Mobile devices and easily accessible wifi Internet connection are changing the digital practices of young people. Convergent multifunctional devices, which support an evergrowing repertoire of communication practices and online 
activities provide significant opportunities for sociability, selfexpression, learning, creativity and participation [8][9].

A recent research project, Net Children Go Mobile (NCGM), conducted in 2014 in seven European countries, Denmark, Italy, Romania, the UK, Belgium, Ireland and Portugal, investigated, using quantitative and qualitative methods, how the changing conditions of Internet access and use - namely, mobile Internet and mobile-convergent media bring greater, less or newer risks to children's online safety (aged 9 to 16) [10]. The Net Children Go Mobile project results, in all 7 countries, including Portugal, evidence that the ways of going online are diversifying with the diffusion of mobile media. Smartphones in particular are becoming an integral part of the media ecologies [11] that children inhabit.

Parental mediation strategies of children's Internet use can be classified into five main categories, as proposed by the EU Kids Online project [12][13].

1) Active mediation of Internet use, where parents engage in activities such as Talking about Internet content while the child is engaging with it, and sharing the online experience of the child by remaining nearby.

2) Active mediation of Internet safety, where the parent promotes safer and responsible uses of the Internet.

3) Restrictive mediation, which involves setting rules that limit and regulate time spent online, location of use and online activities.

4) Technical restrictions, that is, the use of software and technical tools to filter, restrict and monitor children's online activities.

\section{5) Monitoring or checking the record of online activities.}

NCGM research identified gender differences in parental mediation, with girls receiving more active mediation by their parents. Considering the three most popular active mediation strategies - talking about the child's online activities, staying nearby or sitting with the child while she uses the Internet teenage girls are far more mediated than boys [10].

Parents' safety concerns are often one of the reasons for placing more restrictions on the girls' use of the Internet. In restricting girls' access to the Internet more than they do for boys, parents may undermine girls' feelings of competence, which illustrates the potentially long-lasting consequences of such intangible factors [1].

As the Internet is more thoroughly embedded in the lives of children who have access to mobile devices to go online, the conditions of Internet use are increasingly privatized. Consequently, the parental mediation strategies are challenged and have to adapt to ever more pervasive Internet access and mobility [10].

The strategies of parental mediation in the regulation of Internet use cannot be the same whether children use computers or mobile devices. Devices that are perceived as more personal media and have smaller screens, as for example, smartphones, can hinder the strategies of parental mediation. For instance, monitoring can be very difficult if not impossible at all. Considering the new conditions of Internet use by young people, parents need to adapt their mediation strategies. More than ever, parents need to communicate with children about their online experiences [13].

\section{A GENDER PERSPECTIVE ON THE RESULTS OF THE RESEARCH 'GROWING UP WITH SCREENS'}

The report 'Growing Up with Screens' [7] presents the results of the Regulatory Authority for the Media project "Public and Media Consumption", developed in partnership with the Universidade NOVA de Lisboa, Faculty of Social and Human Sciences. The main analytical theme of this edition is the use of electronic media by children (3-8 years-old). It seeks to identify the screen environments (televisions, computers, consoles, mobile phones, tablets...) in which children of these ages live, how they access and use them, how their parents monitor their use and their attitudes and concerns.

The study includes two components:

1. the first national survey on this topic, carried out face-toface in 656 homes, which included a questionnaire for the parents of children aged from 3 to 8 and a questionnaire for children aged from 6 to 8 ;

2. interviews and observations in the homes of 20 families with different profiles and with children aged 3 to 8 who use the Internet.

A gender sensitive analysis to the results presented by the report 'Growing Up with Screens' [7] can disclose technologies as social constructions and the complexity of gender-technology relations.

In what concerns the characterization of mothers and fathers who participated in the research it is interesting to highlight that there are more mothers with higher degrees of education. This is consistent with the statistics of higher education in Portugal (www.dgeec.mec.pt) that reports that approximately $60 \%$ of the graduates are women. Although women have higher qualifications, the professional occupation of the participants in the categories of 'Top Manager / Liberal profession' and 'Board member / Intermediate manager / Business Owner', show no difference between men and women. This situation is in line with research on gender inequality and employment [14] that reports on gender-based segregation in employment, with women under-represented in decision-making positions, in particular, in Management boards across the EU.

The professional occupation of the participants was determined by asking them. It is particularly noteworthy that only women identified themselves as 'Domestic' which means being an unpaid housekeeper. However, $6,2 \%$ of the men were unemployed at the time when the research was conducted, but none of them self-identified as 'Domestic'. This difference between men and women are consistent with the dominant social model where women still have the primary responsibility for care and work within the family [14].

It was mainly mothers (69\%) and fathers (24\%) who answered the questionnaire. Grandparents represent $4 \%$ and other people are residual (2\%). The greater presence of mothers 
is coincident with that verified in surveys directed at older ages (9-16 years), such as the EU Kids Online survey (2010), and suggests the continuity of representation of the mother as the first / main caregiver and companion of the child.

Mothers and fathers are role models for the children in what concerns the use of screens and accessing the Internet. According to the results of 'Growing Up with Screens' [7], at home children aged three to eight commonly have adults using screens and accessing the Internet in common spaces. Contrasting with the use of Internet at home, frequent use of the Internet in the workplace is only slightly above half and its non-use is referred by almost a third of the participants, suggesting low-occupational jobs in both internal communication and information search. There is practically no difference between fathers and mothers in the use of mobile devices, however, there are gender stereotypes regarding the use of fixed devices, such as the desktop computer. The desktop computer is more used by fathers (52\%) than by mothers $(39 \%)$ who use fewer devices that do not allow them mobility at home. Women having the main responsibility of housework implies that they are more often moving through the house, while men can spend more time on self-related activities, working or entertaining themselves [15]. Another interesting result it related to the use of game consoles, fathers use them two times more than mothers. These differences are related to gender stereotypes at the same time that reinforce them, thus exposing children to gender stereotyped models. Considering the importance of parents as role models to children's attitudes and behaviours towards technology (BlumRoss \& Livingstone, 2016), one can understand the importance of making more widely available diverse gender related models on interactions with technologies, namely at school [16].

As it would be expected, taking into account the role models that children have at home and dominant gender stereotypes, boys have more $(84 \%)$ game consoles than girls $(60 \%)$, and girls have more tablets $(68 \%)$ and portable media players $(45 \%)$ than boys $(57 \%)$. Girls' use of technologies is usually associated with communication features [10] and the mobility is not yet a constraint given that they are not at this age expected to be responsible for housework.

As far as television programs are concerned, responses regarding uses are also in accordance with gender stereotypes. Girls (45\%) watch more soap operas than by boys (34\%), as well as reality shows (18\% and $13 \%$, respectively). The boys refer watching more sport programs than girls (39\% and $29 \%$, respectively). Then again gender stereotypes seem to have a preponderant influence on children preferences.

Gender stereotypes are also evident in what concerns games and activities on the Internet: boys play games more often than girls (respectively $28 \%$ and $19 \%$ play every day or almost every day) and $45 \%$ of boys and $54 \%$ of girls do not play. Boys, who refer more to this activity than girls, not only mention them more often as they place them at the top. Only two games are referred both by boys and girls (Candy Crush and Super Mario), and what is really interesting no boy mentions princess games, which are always referred by girls. Restraining the use of the Internet to gender stereotypes can hinder personal, social and professional decisions during the course of life time. In particular, it can prevent girls to choose studies and professions related to technologies. At a time when technologies are ever more central to the fabric of societies it can have an enduring effect on perpetuating gender inequalities.

Children of both sexes seek out the adults in the family to talk about what they see on television and do on the Internet. There is statistically significant difference in terms of age, rising from $52 \%$ at $3-5$ years to $75 \%$ at $6-8$ years. However, more girls than boys talk about what has upset them on the Internet and ask advice on how to act on the Internet. Talking with parents about something that has disturbed them on the Internet shows statistically significant variations by gender ( $20 \%$ of boys, $31 \%$ of girls).

In what concerns gender differences between fathers and mothers there seems to be no differences on active parental mediations strategies. However, the technical restrictions strategies of parental mediation are more used by fathers and towards boys. Blocking or filtering websites has statistically significant differences by sex, with technical restrictions being used with boys being twice than with girls $(30 \%$ and $15 \%$ respectively). Children gender differences show statistically significant values in parental concerns regarding cyberbullying and the risk of the device catching viruses and other technical problems. In both cases, the values for boys far exceed the values for girls: $39 \%$ and $25 \%$, respectively, for cyberbullying; $44 \%$ and $30 \%$, respectively, for technological risks. This difference can be related to the perception of boys being more competent on the Internet and that they can do more things on the Internet without the help of an adult. The claim that my child knows how to do various things on the internet without asking for my help is more corroborated by parents of boys $(56 \%)$ than girls $(38 \%)$. The perception of boys as more independent and self-reliable can increase the need of parents to use technical restrictions to prevent risks and harm.

Regarding to the perception and utility of skills, gender stereotypes are also found. The reference to the benefits of using the internet for children's school performance is more frequent when talking about boys $(71 \%)$ than when talking about girls $(58 \%)$. Boys are perceived as more competent and autonomous on using the Internet. The importance of the skills related to the use of the Internet are also more valued on boys than on girls. These gender differences lead us back again to consider the enduring personal, social and professional impact on the lives of boys and girls, reinforcing gender inequalities.

\section{QUALITATIVE PART OF 'GROWING UP WITH SCREENS'}

The qualitative part of 'Growing Up with Screens' [7] adopted a participatory approach focusing on the processes and dynamics of twenty families with children aged 3 to 8 years old. The field work, developed from May to July 2016, included 3 phases: the observation of the domestic contexts of media use; interviews-talk with the children and the observation of their practices with media in a family context; and semi-structured interviews with parents and, in some cases, siblings. Participants were selected based on a purposive sample considering different family composition and socioeconomic status. 
The table (Table I) characterizes the children who participated in the qualitative part of the research. There were 20 families participating, of which 2 families have 2 children aged 3 to 8 years old, which totals 22 children.

TABLE I. CHILDREN'S CHARACTERIZATION

\begin{tabular}{|c|c|c|c|c|c|c|c|}
\hline & \multicolumn{6}{|c|}{ Age } & \\
\hline & 3 & 4 & 5 & 6 & 7 & 8 & Total \\
\hline Girls & 1 & 2 & 1 & 3 & 0 & 4 & 11 \\
\hline Boys & 1 & 3 & 0 & 5 & 0 & 2 & 11 \\
\hline
\end{tabular}

The age of the mothers ranges from 32 to 45 years old, and the age of the parents ranges from 34 to 69 years old. Almost all the families have both parents living with the children; only two families have divorced parents (one of the families the child lives with the mother and has regular contacts with the father, and the other family the child lives with the mother and her companion), and one family lives together apart. Two other families are the father's second marriage.

The occupation of the parents is mainly on intermediate manager and senior officer level (Table II). Most of the families can be considered to belong to a middle-class socioeconomic status.

TABLE II. PARENTS OCCUPATION

\begin{tabular}{|l|r|r|}
\hline & Mother & Father \\
\hline Top Manager / Liberal Profession & 1 & \\
\hline $\begin{array}{l}\text { Senior officer / Intermediate manager / Business } \\
\text { owner }\end{array}$ & 13 & 13 \\
\hline Administrative / Merchant, Artisan & 3 & 1 \\
\hline Non-administrative / Supervisor, Specialized worker & 2 & 1 \\
\hline Not active (domestic labour, student, unemployed) & & 5 \\
\hline
\end{tabular}

The existence of other children in the house is diverse: 6 of the children are the only children in the family, and 16 have sisters and brothers. Most of the sisters and brothers are older, around 11 years old, and some have grown up siblings, over 20 years old.

All children in these 20 families use the internet on a daily basis. Portable and individualized devices are privileged for access, and the tablet is the preferred device for this activity. These digital devices are used in offline mode for activities such as taking pictures, shooting, painting and playing. For online activities, the motivations are also recreational, highlighting YouTube as the main focus of interest, often in the company of siblings. Although the preferences change with the age, it is observed a convergence of contents: the videos in the Internet that they like most are programs and / or personages that they watch in the television; the children also refer videos with funny stories, music, sports, games and tutorials.
Adults recognize various types of skills acquired by children in the use of technology, from reading and writing, acquisition of vocabulary (in Portuguese and English), creativity, to fine dexterity. In this sense, and in contrast to the mainly passive monitoring by the parents, in the results of the national survey, several families mentioned the active suggestion and demand of applications to develop certain competences. Other functions of the use of digital devices refer to the children's entertainment, to calm or distract them at meal time, or as an incentive for good school performance or behaviour. There are families that do not stimulate and even limit the use of the Internet because they prefer that children entertain themselves with other activities.

In many families, although children know how to download applications, it is the adults who do it; the family intervention also occurs in the use of video communication applications, which are part of the family dynamics in half of the homes observed. There are common concerns about content with violence (especially with boys), dependence on digital devices or the publication of personal information, which is generally prohibited. Families seem to adjust the style of mediation according to the situations, the relationship that exists between the adults and the child, the personality of the child and how it relates to the screens.

Parents value skills provided by digital practices: fine dexterity, problem-solving skills, linguistic, computational, social, digital literacy, and other types of general education. However, there are also concerns, mainly related to violence, inadequacy for the age and how much time that the children spend playing. With the boys, it was also evident the difficulty in dealing with the frustration for not being able to pass one level or losing in the games. In order to avoid these potential negative effects, parental mediation involves a ban on playing (at all or just when the child is disturbed) or, more often, control of the downloaded games either by doing it themselves or by evaluating the games before the children can download them. Several parents refer to "not liking to lose" and "not sharing the game" as behaviours that need to be controlled. A boy ( 4 years old, Family E) "has tantrums" because it has to be him to choose the game and to play first. Another boy ( 8 years old, Family T) when he loses, he cries and gets very disturbed. Girls tend to have a more positive attitude. Two girls (5 and 6 years old, Family $\mathrm{G}$ and Family $\mathrm{H}$ ) change the game and another girl (8 years old, Family S) says "If I cannot win ... anyway I try my best." Another reaction from a girl (8 years old, Family R) exemplifies the more positive attitude, when her parents do not let her play a game anymore she doesn't "make a scene", she simply goes to watch television.

There are many examples of interactions with mothers and fathers in the context of digital practices that are gender stereotyped. For example, the smartphones of mothers are the most used by children, as those of fathers are considered more as work tools. Another example is related to the roles traditionally associated with women. A boy (6 years old, Family I) looks for cake recipes on the Internet and whenever he sees the image of a cake, he says: "Mother, look to the recipe, you're going to do this for me" (Mother, Family I) 
Playing games is an activity with very interesting examples. Notwithstanding that mothers are more present when children are playing games and that they sometimes are role models to children, fathers are often perceived as more capable than mothers. Some boys ask their mother for help when they cannot pass a level in the games. According to his mother, a boy (4 years old) is pleased to see her bypassing the difficulties and advancing in the game:

And sometimes, he is happier to see me playing than to play, because he sees me pass and that is already satisfying because he realizes that he could not go beyond that and if I pass, he is happy just to watch. (Mother, Family D)

A situation, observed while mother and son played a game together, evidences the comparison between the competences of mother and father:

Mother: Come on, let's try it again.

Boy: But you have to carry the fire, otherwise you lose, otherwise you lose, and you and I lose. It has to be Daddy ...

\section{Mother: Why?}

Boy: Daddy knows things better.

They both continue playing.

Mother: That's it, that's it.

Boy: Hey, we did it!

But they run out of water and after all, they did not achieve the objective of the game.

Boy: It was almost. (He sighs) (Family A)

Likewise gender differences are visible on technical mediation strategies. Mothers are often more directly involved in the mediation of children using digital devices, but it is often the father who is responsible for the technical mediation.

My son had a game that I thought "I have to get rid of it" Because it was a game that was ... he had to kill a shark. A huge shark. It was a game with cartoons, it did not look for adults. And the shark killed people. And he liked it a lot, he thought it was very funny. Because the shark had to be fed [with people] ... So, my husband deleted the game. (Mother, Family I)

The influence of the gender stereotypes that exist in society and in particular in the toy and children's products industry has diverse reactions on the part of the families. Few families question or have a critical analysis of the influence industry can have on children. Among the families interviewed, only the $\mathbf{J}$ family was openly opposed to the ideology passed on by Disney products and was concerned about the direct influence that the products had on the imagination of their six-year-old daughter:

Mother: She is very receptive to seeing new things. We try to lead her ... out of Disney as much as possible. I think Disney ...

Father: Disney is all about princesses and princes.
Mother: Things are very ... the pink for the girl, the blue for the boy. The princesses. Boys are only warriors. I hate this idea of girls' toys and boys' toys... When she saw the Disney Junior Channel, sometimes when she was skating, she fantasized a lot of stories while she was practicing. [...] Sometimes I would ask [...] Are you on roller skates, are you talking to whom? She lived in a fantasy world. Not anymore. (Family J, Girl, 6 years)

The Family J seeks to open the daughter's horizons beyond the world of Disney. The parents encourage the girl (6 years old) to see the animated films of European and independent producers. They confess, however, that it is very difficult to fight against the big brands and that the girl is surrendering to the channel Disney Junior and to movies of princesses, like Frozen:

Mother: There are European animated film. It's not just Disney.

Father: We get the European films, like Casa da Magia I read a very good comment. I showed it to her and she liked it.

Mother: I do my best not to buy pink things. That stigma. Or that girls can only do certain things. We try to instil her as much as possible that she can do whatever she wants.

Father: And you have to see other things.

Mother: But it's so hard to fight it. It is very, very hard. The pressure of everything that surrounds us. Of girls wanting to be princesses. I loathe princesses and the idea of the white horse and of the ideal man. This idea will lead the girl to believe that one day her prince will arrive on a white horse. That does not exist. And it has to be fought when she is a little girl (Family J).

Divergent position has the mother of the Family $G$ who relies on the Disney infant and pink universe. The girl is five years old and likes to watch the Nickelodeon channel, which the mother considers to be less infantile and therefore, in her opinion, less appropriate:

This channel [Nickelodeon] she likes it ... but I think that Disney is more infantile, more childlike. More cute. There's Princess Sofia, there's Doctor Toys. She does not like it, she likes some more the other cartoons ... I do not think it's adequate for her age. I think it's more like ... strange dolls. For example, Doctor Toys, you see, they are pretty little dolls, girls, all right. They look like people. The other cartoons only have the trunk, the hands, and two sticks. It is much more adult. That's why I do not like it, not even the graphic aspect ... (mother, Family G).

The results of our research identify gender differences, both on parents and children, in the parental mediation of children's media use. These differences are related to gender stereotypes, which affect boys' and girls' representations and practices of media usage as well as their self-confidence towards digital technologies. 


\section{CONCLUSIONS}

A gender sensitive analysis to the results presented by the report 'Growing Up with Screens' [7], both quantitative and qualitative, disclosed the complexity of gender-technology relations. Technologies are social constructions and as such gender stereotypes influence their access and use. The results bring evidence of the prevalence of gender stereotyped uses of technologies in the Portuguese households with children aged 3 to 8 years old. Not only the access and use of mothers and fathers is highly gender stereotyped, but also the children's activities and parental mediation strategies. One of the most evident results is that mothers and fathers being role models for children and having gender stereotyped behaviour, perpetuates gender inequalities in the use of technologies.

Some examples of gender stereotyped interactions with technology highlighted by this research: fathers use more fixed devices at home than mothers (mothers still have the responsibility of house care and as such they use devices that allow them mobility at home), and fathers use game consoles two times more than mothers. Besides the actual use of technology, the children's perception of how mothers and fathers use technology is also highly gendered. For example, the smartphones of fathers are considered more as work tools and accordingly children mothers' smartphones are the most used by children. Moreover, even when children look after their mothers as examples in games playing, fathers are usually perceived as more capable than mothers. Likewise mothers are generally more involved in the mediation of children using digital devices, but fathers are often the ones responsible for the technical mediation.

Girls more than boys talk about what has upset them on the Internet, and on the other hand boys are perceived as more independent, self-reliable and autonomous on using the Internet. These gender differences can be one of the reasons why parents use more technical restrictions with boys, aiming to prevent risks and harm.

Playing more violent games and the difficulty in dealing with the frustration is more obvious in boys than in girls. Gender stereotypes have a preponderant influence on children behaviours. Media and toys' industries have a major role reinforcing gender stereotypes, and it seems that few families question or have a critical analysis towards their influence on children.

One significant difference, not only statistical but also educational and sociological, is that parents value more on boys than on girls the skills related to the use of the Internet. These differences affect representations and practices of media usage, as well as girls' and boys' self-confidence towards digital technologies, reinforcing gender inequalities.

Research has brought evidence that overall inequalities in gender and socioeconomic status remain influential in determining who uses digital and online media to learn, create, communicate and participate and that only a small minority of children are fully able to access the full range of opportunities presented by digital media [2]. Gender inequalities in technologies access and use have an enduring impact in future decisions about studies and professions related to technologies. Boys and girls should be encouraged to express aspects of selfidentity that transcend stereotyped gender categories, broadening the range of available options of experiences and identities [17]. Considering the importance dominant gender stereotyped practices of families, one can understand the importance of school to expose children to more diverse gender related models on interactions with technologies.

\section{REFERENCES}

[1] OECD, Students, Computers and Learning: Making the Connection, Paris, OECD Publishing, 2015.

[2] A. Blum-Ross and S. Livingstone, Families and screen time: Current advice and emerging research, Media Policy Brief 17, London, London School of Economics and Political Science, 2016.

[3] L. S. Clark, The Parent App. Understanding families in the digital age, Oxford, Oxford University Press, 2013.

[4] J. Wajcman, "From Women and Technology to Gendered Technoscience", Information, Communication \& Society, vol. 10, n. 3, pp. 287-298, 2007.

[5] K. Grint, and R. Gill, The gender-technology relation: Contemporary theory and research, Oxford, Blackwell Books, 1995.

[6] W. Faulker, "The technology question in feminism: a view from feminist technology studies", Women's Studies International Forum, vol. 24, n. 1, pp. 79-95, 2001.

[7] C. Ponte, J. A. Simões, S. Batista, A. Jorge and T. S. Castro, Growing Up with Screens, Crescendo entre Ecrãs: Usos de meios eletrónicos por crianças (3-8 Anos), Entidade Reguladora para a Comunicação Social, 2017.

[8] G. Goggin, "The Internet, Online and Mobile Communications and Culture". In S. Cunningham, G. Turner, Eds., The Media and Communications in Australia: 3rd Edition, Australia, Allen and Unwin, 2010, pp. 237-258.

[9] G. Goggin and L. Hjorth, "Introduction: Mobile Media Research - State of the Art". In G. Goggin and L. Hjorth, Eds., The Routledge Companion to Mobile Media, New York: Routledge, 2014, pp. 1-8.

[10] G. Mascheroni and K. Ólafsson, Net Children Go Mobile. Risks and Opportunities, Second edition, Milano, Educatt, 2014.

[11] M. Ito, et al., Hanging out, messing around, and geeking out: Kids living and learning with new media, Cambridge, MA, MIT Press, 2009.

[12] S. Livingstone, L. Haddon, A. Görzig, and K. Ólafsson, Risks and safety on the internet: The perspective of European children, Full findings, London, LSE, EU Kids Online, 2011.

[13] G. Mascheroni, M. F. Murru, E. Aristodemou, and Y. Laouris, "Parents. Mediation, selfregulation and co-regulation". In B. O'Neill, E. Staksrud, \& S. McLaughlin, Eds., Towards a better internet for children? Policy pillars, players and paradoxes, Göteborg, Nordicom, 2013, pp. 211-225.

[14] European Institute for Gender Equality, Gender in Employment. Vilnius, EIGE, 2016.

[15] R. Ribeiro, L. Coelho, and A. Ferreira-Valente, "Unemployment and gender equality within the family in portugal", Ex aequo, vol. 32, pp. 69$85,2015$.

[16] E. Ferreira, "The co-production of Gender and ICT: Gender stereotypes in schools", The first Monday, (accepted for publication).

[17] H. Jenkins and J. Cassell, "From Quake Girls to Desperate Housewives: A Decade of Gender and Computer Games". In Beyond Barbie and Mortal Kombat: New Perspectives on Gender and Gaming, Y. Kafai, C. Heeter, J. Denner, and J. Sun, Eds. Cambridge: MIT Press, 2008, pp. 420. 